\title{
Some notes on Mindsponge in infant cognition
}

\author{
Tam-Tri Le \\ Centre for Interdisciplinary Social Research \\ Phenikaa University, Hanoi, Vietnam \\ Written in Ho Chi Minh city, on 9 June 2021 \\ OSF Preprints, DOI: 10.31219/osf.io/jvu94
}

Infant cognition is the start of developmental psychology. Cohen and Cashon (2007) summarized popular theoretical approaches, major findings, as well as new methodologies in contemporary infant cognition research [1]. They also presented their proposed principles of information processing in infants, which aligns with the approach of connectionist modeling [2]. Referring to the information processing framework Mindsponge [3,4], I briefly note some personal thoughts regarding infant cognition for future further consideration as follows.

a) Infants lack stored information to use as references. By accumulate more information as resources for cognitive processes, young children can gradually become capable of higher (more complex) logical thinking. For example, regarding object permanence, I speculate that the lack of abstract concepts and representations in language causes infants to rely more on direct and immediate perception.

b) Infants have a limited information filtering system, which is both the cause and consequence of the first issue presented above. Newly acquired information can easily enter the mind as accepted beliefs in infants (without facing as many evaluations like in adults). I speculate that the infant brain naturally prioritizes such streamlined acceptance of information to overcome the lack of information; and this may be examined empirically through the study of infant brainwave.

c) As infants develop the construct of self gradually over a long period with different stages [5], I speculate that the early infant mindset does not utilize the 'self' construct as the central priority nor as the connection central node for meaning (information's values in relation to oneself). Probably, this 'mindset' is simply a set of stored neutral information. This may help explain the loss of infant memory in favor of 'meaningful' information in later stages of cognitive development, especially with the shift to using language ('shortcut' for concepts).

\section{References}

1. Cohen, L. B., \& Cashon, C. H. (2007). Infant Cognition. In W. Damon \& R. M. Lerner (Eds.), Handbook of Child Psychology (p. chpsy0205). John Wiley \& Sons, Inc. https://doi.org/10.1002/9780470147658.chpsy0205 
2. Cohen, L. B., Chaput, H. H., \& Cashon, C. H. (2002). A constructivist model of infant cognition. Cognitive Development, 17(3-4), 1323-1343. https://doi.org/10.1016/S08852014(02)00124-7

3. Vuong, Q. H. (2016). Global Mindset as the Integration of Emerging Socio-Cultural Values Through Mindsponge Processes: A Transition Economy Perspective. In J. Kuada (Ed.), Global Mindsets: Exploration and Perspectives (pp. 109-126). Routledge. https://doi.org/10.4324/9781315736396-8

4. Vuong, Q. H., \& Napier, N. K. (2015). Acculturation and global mindsponge: An emerging market perspective. International Journal of Intercultural Relations, 49, 354367. https://doi.org/10.1016/j.ijintrel.2015.06.003

5. Case, R. (1991). Stages in the development of the young child's first sense of self. Developmental Review, 11(3), 210-230. https://doi.org/10.1016/0273-2297(91)90010-L 